\title{
Factors Affecting Delegation Authority toward Employees Performance
}

\author{
Adnan Alhosani ${ }^{1}$, Rosman Md Yusoff ${ }^{2}$, Fadillah Ismail ${ }^{3}$, Fazal Ur Rehman ${ }^{4}$ \\ 1,3,4FPTP, Universiti Tun Hussein Onn Malaysia, Parit Raja, Johor, Malaysia \\ 2PPUK, Universiti Tun Hussein Onn Malaysia, Parit Raja, Johor, Malaysia \\ ${ }^{4}$ COMSATS Institute of Information Technology, Attock Campus, Pakistan \\ fazal_marwatpk@yahoo.com
}

\begin{abstract}
Employees are the key asset of every organization and their performance can influence the goals and objectives of organizations in a positive or negative way. The aim of this study is to develop a theoretical framework in relations to examine the effects of employee's satisfaction and participation, delegation authority and empowerment on employee's performance in UAE organizations. Specifically, to get an in-depth understanding of the linkage between delegation authority and employees performance with emphasize on (employee participation and employee satisfaction). This study is only limited to Dubai organizations and future research may be conducted in other countries as well as can assess the moderating role in the defined variables. By integrating employee's satisfaction and participation, delegation authority and empowerment, and employee's performance literature, the main contribution of this paper is the analysis of defined variables in Dubai organizations with emphasize on new challenges and to boost up the gap of relevant literature.
\end{abstract}

Keywords: Delegation of Authority, Empowerment, Employee Performance

\section{Introduction}

The Arab social setting similar like others is very special and full of attractive features. Historically, dialect and religion are profoundly entwined, family, and tribe traditions are assuming a significant part of the culture. Beside globalization and modernization, the priorities of the Gulf district, including UAE, look to make knowledge economies. According to (Sabri, 2004; 2012), the Arab managers and leaders feel hesitation to assign authority to others and most often organize the necessities of family and companions, and the requirements of the associations. The scenario which has been affirmed by the GLOBE study (House, Javidan and Dorfman, 2001; House, Hanges, Javidan, Dorfman and Gupta, 2004) have found that self-assurance (exemplified by race-saving, dependence on technique and selfcenteredness) is a standout amongst the huge qualities displayed by Arab leaders and managers. As indicated by (Al-Jammal, Al-Khasawneh, and Hamadat, 2015) those employees who are occupied with their duty and committed to their companies can contribute to the organization benefits with good margin including lesser worker turnover and higher proficiency. Delegation of authority may support the lesson of workers in any company and it makes the employee have a fearless environment and feeling of having a place full of features for the leaders in an organization.

Besides, delegation authority is a fundamental subject for the company. As the impact of authority delegation may help in gaining competitive advantage, increase revenue and viability in assignment culmination. In a similar strain, they may express that entrustment of power has reduced the operational loads of the supervisors, has invented contribution and confidence between the administration and the representatives which encourage worker's fulfilment. Some studies (Kombo, Obonyo, and Oloko, 2014; Kiiza and Picho, 2015) have validated that the use of authority delegation can assist workers' viability and improve the leaders' capacity to maintain their duties, keep moving on towards commercial concerns, workers' reliability, and accomplish execution effectiveness. Competencies can be said to be the main thrust behind associations' development and value. As worker competencies are the connections between the earnings of products and the workers' involvement in the operations (Anyadike, 2013), as worker competencies are the consequence of effectiveness and practise of association means.

Worker competencies are viewed as the competency assessment concern with the capacity to deal with 
the workload, finishing the work on time with minor mistakes, and capacity to work with a great extent unsupervised, accomplishment valued as in time utilisation. Therefore, due to the importance of the above-mentioned factors, this study has the objective to propose a model (employee's satisfaction, employee's participation, empowerment, and employee's performance). In Gulf organizational setting, precisely, it is interesting to understand the mediating role of empowerment between employee's satisfaction employee's participation and employee's performance. This study may be helpful to HR managers in the various sectors at gulf to formulate better management policies to improve the level of performance, increase profitability, and efficiency to achieve the organizational objectives.

\section{Literature Review}

Employee Participation: In Emiratis and the Arab States, specifically in UAE, leaders prefer to hire local to get engage them in the working environment. Nevertheless, nearly three of every four employees are not locked in or effectively disengaged at work. This demonstrates that there is a vast potential to expand the engagement levels, specifically when talking among UAE nationals. A recent representative engagement meta-analysis study has affirmed that associations who possess greater engagement of local workers are providing better opportunities to accomplish the hierarchical results such as income and profitability (Gallup, 2016). However, the participation of employee's in decision making is the degree where managers urge to share or take an interest in hierarchical basic decision making. The managers may think about to get a better and ideal style that enables the organization to accomplish the outcome objectives. Participative style of management is also known as a shared authority, representative strengthening, worker association, participative basic leadership, scattered initiative, open-book management, or democracy in industries.

The fundamental idea includes power-sharing approaches, where the working environment impacts are shared among team members. Such power-sharing plans may involve a different representative of associations, can better plans about co-workers working conditions, critical thinking, and basic leadership. At a point, where everybody in an association takes interest in the basic leadership process and hierarchical correspondence are substantially more successful and can deliver productive outcomes (Johnson, 2004). Johnson (2004) portrays employee support as a blend of responsibility and hierarchical citizenship. The cutting-edge of business has acknowledged the genuine hierarchical with focus on the capacity that lies in the profundities of individual and their support to convey super standard yields. The key to beat contenders has turned out to be progressively subject to the levels of execution conveyed by an association's workers (Izak, 2008). Glaser (2005) cites William James saying: "The most profound guideline of human instinct is to be valued".

Armstrong and Baron (2005) have concurred and asserted that non-financial inspirations can be given for the better execution of administration, by giving chances to get success, and in addition to improving occupation engagement and responsibility. Jackman and Strober (2005) have depicted a magnificent connection among managers and employees where the input is given all the time, and it is followed up in many ways to enhance the worker execution capabilities and in addition to conceive the advancement. However, in modern organizational setting the democratization is highly preferable. As the participation of employees in decision making can contribute to organizational objectives, enhance employee's motivation, performance and confidence, and can bring innovation (Irawanto, 2015).

Employee Satisfaction: The sociocultural standard is one of the key factors to enhance the UAE national's career decision-making process and opinion regarding what is and what isn't an appropriate profession road. For example, Harry (2007) and Al-Ali, (2008) have stretched that Arabian Gulf society puts more eminence to public sector positions rather than private segments (Al-Asfour, and Khan, 2014; Salih, 2010). Therefore, empowerment may be a huge part in employee fulfilment for advancing their execution in the organization. Also, empowerment may be one of the pivotal factors toward improvement and enhance the people thinking's, carries on, motivation and self-sufficiently, and controlling the different operational activities. It is simply the inclination control of one's own fate (Heathfield, 2012). Harter, Schmidt and Hayes (2002) have demonstrated towards a causal model ought 
to be created by investigating the summed-up way of workers' satisfaction and engagement towards short-term results. Furthermore, Khan, Jam, Akbar, Khan and Hijazi (2011) have verified that those organizations which have work inclusion culture, their employee are more dedicated with organizations than those organizations that don't include their employee in decision making. Sowmya and Panchanatham (2011) have uncovered that activity fulfilment is subject to chief conduct, collaborator conduct, pay and advancement, employment and working condition, and most important hierarchical perspectives.

The workers may have a huge slant towards idealistic supervisory conduct and wonderful authoritative setup. Such as Bhatti, Nawab and Akbar (2011) have observed that interest in worker cooperation within organization indicates better outcomes, high representativeness, dedication and efficiency, advancement of wanted information, abilities, states of mind and different practices, which brings about higher occupation fulfilment and authoritative execution. Meanwhile, Oluwakemi, Michael and Tunde (2011) have shown that preparation is an instrument that can help with building a more dedicated and profitable workforce and can prompt more noteworthy duty and less worker turnover. However, in today competitive environment, the employee's participation in the decision-making process is highly preferable to enhance the team learning. Further, the employee's participation in decision making has a positive significant relationship with job satisfaction (Saha and Kumar, 2017).

Empowerment: Empowering workers to lead to enable organization quick responsive, flexible and can prompt a change in both authoritative and individual performance (Meyerson, and Dewettinck, 2012). Individuals having power may feel too much vitality and control in an organization (Shabaani, Kheyri, Atefeh, Rahemipoor, Mahdieh, 2012). Whitman, Van Rooy and Viswesvaran (2010) have proposed a technique of execution relations among various units inside organizational operations. The study has noted a linkage among various unit level exhibitions. Specifically, a strong linkage was noted between unit level occupation fulfilment and unit level criteria, such as customer's loyalty, profitability, and hierarchical citizenship actions. However, Tuuli and Rowlinson (2010) have divided it into mental strengthening and employment execution to examine the capacity, inspirations and chance to measure mediation between strengthening and execution. It was noted that strengthening had an immediate and constructive outcome on work execution and can improve the inspiration level, provide opportunity and power of execution. The investigation has shown that engaged workers display positive execution practices, and psychological empowerment which is a profitable resource for the organization to seek after their coveted outcomes. Therefore, the employee's empowerment is the vital factor in management practices to maintain the service quality. Evidently, Islam (2016) has noted that employee's satisfaction and service quality are widely depending on the employee's empowerment. As empowerment is the new approach of management to develop their organization and fulfil the requirements of the 21th century (Serami, 2015).

Employee Performance: The vast majority of the study that relates strengthening and execution at the individual level of analysis, normally concentrating on the relationship between work design and job execution. Meanwhile, there are few connections between work improvement and company execution (Patterson et al., 2004). Measures of HRM ordinarily incorporate occupation improvement and ability upgradation. Studies have observed HRM be emphatically connected with organization execution (Guthrie, 2001). Furthermore, Grimaldi (2005) has clarified that overseeing worker execution incorporates way such as: arranging work and setting desires, checking and estimating execution, building up the ability to perform, intermittently evaluating execution, perceiving, and remunerating execution. Refining worker execution often requires capability in specific abilities. Capabilities are detectable, quantifiable examples of aptitudes, information, capacities, practices, and different qualities that an individual need to perform work parts or word related capacities effectively. According to Huselid and Becker (2005), employee's execution reminds individual job responsibilities that being occupied isn't the same as creating a result. It advises us that preparation, solid responsibility and bunches of diligent work alone are not sufficient for successful outcomes.

As management execution diverts our endeavors from hectic toward adequacy. Richard et al. (2009) say 
that hierarchical execution includes three zones specifically; benefit returns on resources, rates of profitability, item showcase execution (deals, a piece of the overall industry) and investors return. In many associations, performance is supervised through adjusted scorecard procedure where execution is checked and estimated in various measurements, for example, money related execution, client benefit, social obligation and worker stewardship. Laurie (2010) brings up that execution pointers can be estimated as far as; business execution and results, advertise standing, advancements, efficiency, performance etc. Therefore, employee's performance is the key factor for every organization to achieve its objectives. Employees performance is an "indicator of financial or other outcome of the employee that has a direct connection with the performance of the organization as well as its achievement, further revealed that working atmosphere, leadership, team and co-worker relationship, training and career development, reward program, guidelines and procedures and workstation wellbeing as well as employee engagement are major factors that determine employee performance" (Inuwa, 2016).

\section{Research Framework}

Based on Figure 1, factors of employee participation and employee satisfaction are independent variables and employee performance is the dependent variable. Also, empowerment has the mediating role between the relationships. The illustration of the theoretical framework:

Figure 1: Theoretical Framework (Adapted from Walker, 2007; Khan et al., 2011; Grimaldi, 2005; and Meyerson \& Dewenttinck, 2011)

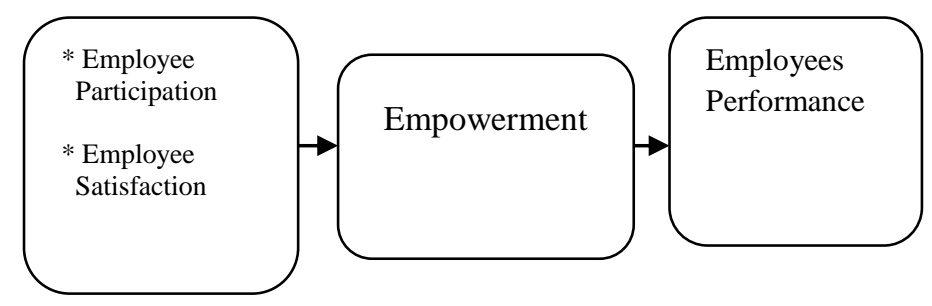

\section{Suggestions}

Numerous studies, such as, Hashim, Ahmed and Jaradat (2013) have appreciated the designation of power to positively influence the loyalty of employees with organizations and the sense to successfully deliver the assigned task. In this manner, the worker will attempt to legitimize the power assigned to them by demonstrating uplifting disposition in playing out the errands and capacities by means of compelling usage of the accessible resources. In associations, powerful designation allows subordinates to consolidate the application of skills at the workplace, and the approaches to successfully achieve the organizational objectives (Eddie, 2002). However, to effectively enhance the employee's contribution at the workplace, to usefully use their energies, it is highly appreciated to give them a chance with full power and confidence, freedom in the usage of skills can result in something unique. Such power and confidence can upgrade the level of positivity, and the feelings to successfully achieve the organizational objectives. It can sustain the level of performance as the employees will try to compete with their colleagues, to show their image of capacity that will result in better performance at the workplace. Therefore, it is highly recommended to empower human resources to upgrade their level of motivation, feelings, performance, and job satisfaction.

\section{Conclusion and Recommendations}

Along these lines, if power delegation isn't appointed to the workers, implementation of undertakings may be unproductive. Giving personnel the privilege to complete or officially correct increment to increase their spirit for better performance. This may make the workers feel that they are part and parcel of the associations to accomplish the mission and vision of it. Subsequently, designation of administrative errands to personnel can affect the worker's execution and it may help the directors to 
concentrate on different activities for the advantages of association. Along these lines, the appointment of power is an administrative practice. As the designation of power demonstrates that the leaders believe in the capacity of their subordinates to follow up for their benefit or for the sake of association. Representatives may see this as a type of trust and endeavor to legitimize the trust through the compelling release of duties anticipated from them. Likewise, worker empowerment has broadly been perceived as a fundamental supporter of authoritative accomplishment with numerous creators which is an immediate connection between the level of employee empowerment and employee execution, job satisfaction from employee and worker duty. Engaging workers, associations often empower to be more adaptable, responsive and can prompt upgrades in both individual and organizational performance. However, this study is only limited to gulf organizational settings, while future studies can be completed in a quantitative manner in the other parts of the world.

\section{References}

Al-Jammal, I., Al-Khasawneh, J. A. \& Hamadat, A. M. (2015). The impact of the delegation of authority on employees' performance at great IRBID municipality: Case study. International Journal of Human Resource Studies, 5(3), 61-72.

Anyadike, N. O. (2013). Human resource planning and employee productivity in Nigerian public organization. Global Journal of Human Resource Management, 1(4), 56-68.

Al Ali, J. (2008). Emiratisation: Drawing UAE nationals into their surging economy. International Journal of Sociology and Social Policy, 28(9), 365-379.

Al-Asfour, A. \& Khan, S. A. (2014). Workforce localization in the Kingdom of Saudi Arabia: issues and challenges. Human Resource Development International, 17(2), 243-253.

Armstrong, M. \& Baron, A. (2005). Managing performance: Performance Management in Action. London, UK: Chartered Institute of Personnel and Development.

Bhatti, K. K., Nawab, D. S. \& Akbar, D. A. (2011). Effect of direct participation on organizational commitment. International Journal of Business and Social Science, 2(9), 15-23.

Eddie, S. (2002). Don't be afraid to delegate. Department of Public Administration and Development Studies, University of South Africa, 21(2), 66-79.

Gallup, Q12 Meta-Analysis Report. (2016).

Glaser, J. E. (2005). Creating wealth: Change I-Thinking to We-Thinking \& Build a Healthy, Thriving Organization. Avon, USA: Platinum Press.

Grimaldi, L. (2005). Study proves recognition pays off. Meetings \& Conventions. 30-40.

Guthrie, J. P. (2001). High-involvement work practices, turnover, and productivity: Evidence from New Zealand. Academy of Management Journal, 44(1), 180-190.

Harry, W. (2007). Employment creation and localization: the crucial human resource issues for the GCC. International Journal of Human Resource Management, 18(1), 132-146.

Harter, J. K., Schmidt, F. L. \& Hayes, T. L. (2002). Business-unit-level relationship between employee satisfaction, employee engagement, and business outcomes: a meta-analysis. Journal of applied psychology, 87(2), 268.

Hashim, T., Ahmed, A. \& Jaradat, N. (2013). The impact of structural empowerment in achieving psychological empowerment in the Jordanian public organizations. Journal of Hebron University for Research, 8(1), 44-56.

Sabri, Socio-cultural values and organizational culture, H. A. \& Becker, K. (2004). Islam and Business, 123-45, New Brunswick, NJ: Haworth Press.

Sabri, H. A. (2012). Re-examination of Hofstede's work value orientations on perceived leadership styles in Jordan, International Journal of Commerce and Management, 22(3), 202-218.

Heathfield, S. M. (2012). Training: Your investment on people development and retention. Human Resource Journal, 56(2), 12-17.

Huselid, M. A. \& Becker, B. E. (2005). The workforce scorecard: Managing human capital to execute strategy. Harvard Business Review Press.

Inuwa, M. (2016). Job Satisfaction and Employee Performance: An Empirical Approach. The Millennium University Journal, 1(1), 2016.

Irawanto, D. W. (2015). Employee participation in decision-making: evidence from a state-owned 
enterprise in Indonesia, Management, 20(1), 159-172.

Islam, M. (2016). The impact of employee empowerment on employee satisfaction and service quality: empirical evidence from financial enters prizes in Bangladesh, Business: Theory and Practice, $17(2), 178-189$.

Izak, W. D. (2008). A critical analysis of factors that influence employee work performance. Department of Master of Business Administration, South Africa, 1-192.

Jackman, J. M. \& Strober, M. H. (2005). Fear of feedback. In: Harvard Business Review on Appraising Employee Performance. USA: Harvard Business School Publishing Corporation, 29-46.

Johnson, M. (2004). The new rules of engagement: Life-work Balance and Employee Commitment. London: Chartered Institute of Personnel and Development.

Khan, T. I., Jam, F. A., Akbar, A., Khan, M. B. \& Hijazi, S. T. (2011). Job involvement as a predictor of employee commitment. International Journal of Business and Management, 6(4), 252-262.

Kiiza, P. \& Picho, E. O. (2015). Delegation and staff commitment in the school of finance and banking in Kigali, Rwanda: An empirical study. Global Journal of Commerce and Management Perspective, $4(3), 50-54$.

Kombo, B. W., Obonyo, G. O. \& Oloko, M. (2014). Effects of the delegation on employee performance in savings and credit cooperative societies in Kisii County, Kenya. The International Journal of Business and Management, 2(7), 22-31.

Laurie, J. M. (2010). Management and Organizational Behavior FT Prentice Hall.

Meyerson, G. \& Dewettinck, B. (2012). Effect of Empowerment on Employees Performance. Advanced Research in Economic and Management Sciences, 2, 40-46.

Oluwakemi, A. O., Michael, O. \& Tunde, E. (2011). Enhancing employees' commitment to organization through training. International Journal of Business and Management, 6(7), 280-286.

Patterson, M., Warr, P. \& West, M. (2004). Organizational climate and company productivity: The role of employee affect and employee level.Journal of Occupational and Organizational Psychology, 77(2), 193-216.

Richard, P. J., Devinney, T. M., Yip, G. S. \& Johnson, G. (2009). Measuring organizational performance: Towards methodological best practice. Journal of management, 35(3), 718-804.

House, R. J., Javidan, M. \& Dorfman, P. (2001). Project GLOBE: An introduction, Applied Psychology: An International Review, 50(4), 489-505.

House, R. J., Hanges, P. J., Javidan, M., Dorfman, P. W. \& Gupta, V. (2004). Culture, Leadership and Organizations: The GLOBE Study of 62 Societies, Thousand Oaks, CA: Sage.

Saha, S. \& Kumar, S. P. (2017). Influence of participation in decision making on job satisfaction, group learning, and group commitment: empirical study of public sector undertakings in India. Asian Academy of Management Journal, 22(1), 79-101.

Salih, A. (2010). Localizing the private sector workforce in the Gulf cooperation council countries: A study of Kuwait. International Journal of Public Administration, 33(4), 169-181.

Saremi, H. (2015). Empowerment as a New Approach in the Management, Proceedings of the International Conference on Global Business, Economics, Finance and Social Sciences (GB15_Thai Conference) ISBN: 978-1-941505-22-9 Bangkok, Thailand, 20-22 February 2015 Paper ID: T567.

Sowmya, K. R. \& Panchanatham, N. (2011). Factors influencing job satisfaction of banking sector employees in Chennai, India. Journal of Law and Conflict Resolution, 3(5), 76-79.

Taktaz, Behzad., Shabaani, Sedigheh., Kheyri, Atefeh Rahemipoor Mahdieh. (2012). The Relationship between Psychological Empowerment and Performance of Employees, SINGAPOREAN Journal of business economics, and management studies, 1(5), 19-26.

Tuuli, M. M. \& Rowlinson, S. (2010). An exploratory study of the contextual meaning and consequences of empowerment in project teams.

Walker, G. B. (2007). Public participation in participatory communication in environmental policy decision-making: From concepts to structured conversations. Environmental Communication, 1, 99-110.

Whitman, D. S., Van Rooy, D. L. \& Viswesvaran, C. (2010). Satisfaction, citizenship behaviors, and performance in work units: A meta-analysis of collective construct relations. Personnel Psychology, 63(1), 41-81. 